\title{
AIRPORT BENCHMARKING AND SPATIAL COMPETITION: A CRITICAL REVIEW
}

\author{
Pavlyuk Dmitry \\ Transport and Telecommunication Institute \\ Lomonosova 1, Riga, LV-1019, Latvia \\ Ph.: (+371)29958338.E-mail: Dmitry.Pavlyuk@tsi.lv
}

\begin{abstract}
During the last two decades the European airport industry is liberalised and turned to competitive market environment. This fact attracts an increasing scientific and practical interest to analysis of airport efficiency and its determinants, as well as different aspects of airport competition. This paper contains a critical review of existing researches in these two areas - airport efficiency and spatial competition among airports. We analysed modern approaches to airport benchmarking, their advantages and shortcomings, and systematised a wide range of related academic studies. We paid special attention to empirical researches of spatial competition as a factor affecting airport efficiency. Despite the fact of a well-developed theory of spatial competition and signs of its growing effects in the airport industry, we discovered a lack of studies devoted to the relationship between airport efficiency and spatial competition.
\end{abstract}

Keywords: airport efficiency, benchmarking, spatial competition

\section{Introduction}

The legislative liberalisation process of the EU air transportation market was completed in 1997 [1-3]. Nowadays all European airlines can provide connections between any origin and destination airports without any restrictions (excluding that related with airports' capacity). Liberalisation of the air transport industry also concerned airport enterprises and initialised significant changes of airports ownership and management. Airlines, operating in a competitive environment [4], gained an option to choose partner airports and therefore obtained influence possibilities. Those changes forced airports, originally considered as natural monopolies, to adapt to new, competitive market conditions. Besides these institutional changes on the air transportation market, there are other sources of increasing competition pressure. Development of high-speed rails, interregional bus transportation and, generally, transport networks also can be considered as an additional factor influencing competition between airports [5].

A competitive industry advances severe claims for enterprises' capitalisation and efficiency. Historically managed by government, many airports were involved into privatisation process to attract private investments and improve operational efficiency. Beginning from 1987, when UK government sold its seven major airports (including London Heathrow, Gatwick, and Stansted) to a private sector firm (British Airports Authority), many European airports became partly or completely private. Being under government ownership, airports' management was oriented (in an ideal case) to maximizing social welfare, at country and regional levels. After privatisation, these objectives were superseded by profit maximisation, usual for a commercial marketplace. One of main sources of company profit maximisation is operational efficiency, so efficiency estimation and improvement became a subject of interest of privately managed airports [6].

Airport efficiency benchmarking can serve different purposes [7] and has important implications for a number of stakeholders. Scotti [8] outlines the following interested parties:

- Airports management require efficiency comparison between airports to improve airport operations and enhance its standing in a competitive environment.

- Airlines management is interested in identifying of efficient airports for their operational activities.

- Municipalities require efficient airports for attracting businesses and tourists into a region.

- Policy makers need for benchmarking for airport improvement programs for making optimal decisions about resource allocation. 
There are several well-known scientific approaches to efficiency estimation, but their applications to the airport industry are related with additional industry-specific complexities. The majority of efficiency estimation methods are based on comparison of economic agents having comparable resources. Concerning utilised resources, European airports are very heterogeneous. There are a set of social, climate, and economic conditions which make airport environment conditions heavily compatible. Also airports are significantly differentiated on the base of average passenger income and trip purposes (business or leisure), which also can be considered as an obstacle for airport comparison and efficiency estimation. Another benchmarking problem is related with a specific type of competition between airports. The legislatively competitive environment doesn't guarantee competition itself. Competition between airports is limited by their geographical location and obviously has a spatial component. Although number of European airports is increasing during last decades [9], there are some geographical areas where a competition pressure is weak or absent. European legislative authorities try to compensate this lack of competition pressure by different forms of regulation [10], which also complicates airport benchmarking.

Significant demand for airports benchmarking from different stakeholders in connection with task complexity attracted academic researchers to pay attention to this problem. There are more than a hundred research papers, published during last two decades, are devoted to airports efficiency estimation. The most significant reports are the Global Airport Performance Benchmarking Reports 2003-2011 produced by Air Transport Research Society (ATRS) [11], the Airport Performance Indicators and Review of Airport Charges reports by Jacobs Consulting, the Airport Service Quality programme by Airports Council International. Some local authorities which control the airport sector also provide their own benchmarking reports, e.g. Avinor AS (Norway) [12], Civil Aviation Authority (UK) [13], and others. Many related researches are also executed within the bounds of the German Airport Performance (GAP) research project, a joint study between three German universities

This paper contains a critical review of exiting airport efficiency researches in respect of used approaches and mentioned empirical difficulties. We pay special attention to spatial competition between airports and taking it into account in airport benchmarking.

\section{Airport Efficiency Benchmarking: Theory and Applications}

\section{The airport business model}

A classical definition refers economic efficiency [14] as usage of available resources (inputs) to maximise the production of goods and services (outputs). For the airport industry defining of inputs and outputs is not straightforward. Currently, an airport is considered as a connection hub between a public (serving passengers and cargo) and an airline (serving aircraft fleet movements) [15]. Airport outputs for these two groups are different - air passenger movements (APM) and air transport movements (ATM). A choice of output specifications is important for further efficiency estimation and can lead to different results and conclusions (see, for example, Pels [16] for a comprehensive discussion).

Concerning airport activity, both APM and ATM outputs are not homogeneous. There are two main components - passengers and cargo, which obviously have different 'handling' processes. A frequently used unit, which integrates passenger and cargo outputs, is a work load unit (WLU). Usually WLU equals to 1 passenger or $100 \mathrm{~kg}$ of cargo. Evidently a WLU is a weak indicator, but quite attractive and frequently used due to its simplicity.

Nowadays, activity of airport enterprises is not limited with aeronautical services, but includes parking, retailing, food and beverages, passenger access, and other services. Today these non-aeronautical services, originally considered as complementary, play an important role in the airport business [17]. According to ATRS reports [11], a share of non-aeronautical revenues is increasing during the last decade and for some European airports exceeds 50\% (for example, for German busiest Munich and Frankfurt airports). Thereby these diverse non-aeronautical activities became an important component of overall airport performance.

Financial indicators can be considered as an alternative to physical measurement of airport outputs. The most frequently used are operational costs and revenues. Usage of financial indicators allows smoothly handle diverse airport activities, but requires information about local prices and airport-specific conditions (like government subsidies, etc.).

Recently some researches also included some negative outputs into airport benchmarking. These undesired outputs can have different forms like environmental emission and noise [18] or passenger delays [19]. 
Resources, utilised by airports, and airport-specific conditions are even more heterogeneous than outputs, and their definition is quite challenging. The primary set of resources usually includes labour resources (e.g. number of employees) and infrastructure resources (number of runways, airport surface area, number of terminal or gates, number of check-in desks, number of baggage reclaim belts). All materials and outsourced services are usually included in financial form. Non-aeronautical resources (like parking spaces, retail points, etc.) should also be included into consideration.

A range of factors affecting airport performance is very wide and includes airport ownership and management structure, hub status, region-specific characteristics like tourist- and business-attractiveness, climate and whether conditions and others. Also from modelling perspective, airport physical outputs can be considered as resources for financial outputs.

Summarising, we can note a great variety of approaches to the airport business model, its outputs and resources. Recently several comprehensive voluminous reviews of airport empirical studies were published [13], [20].

\section{Airport benchmarking techniques}

The theory of efficiency estimation provides a wide range of estimation methods with their own advantages and limitations. Scientific approaches, used for airport benchmarking, start from relatively simple linear indexes, but further include more complicated frontier-based models. Hirschhausen and Cullman [21] presented an excellent review of methodologies used for airports benchmarking.

\section{Partial factor productivity indicators}

The simplest one-dimensional way of efficiency estimation is a direct ratio of a chosen airport output to a given resource used. Indicators, constructed on the base of this strategy, are called partial factor productivity (PFP) indexes. Due to a great diverse of airport outputs and inputs, the range of PFP indexes is very wide. PFP indexes are not related to overall airport's efficiency, but reflect a particular aspect of its activity [22]:

- Labour productivity indexes - APM per employee, ATM per employee, WLU per employee.

- Infrastructure productivity indexes - APM per terminal, WLU per airport's surface square meter, ATM per runway.

- Financial performance indexes - operational costs per WLU, overall/aeronautical revenue per WLU, overall revenue to expenses ratio.

Nowadays PFP indexes for undesired outputs are also frequently used - average delays, delay minutes per ATM, green gas emission per ATM, etc.

PFP indexes are widely used by airport management staff, because the meaning of a PFP indexes and sources of its values are obvious, calculation of PFP indexes is elementary, and each index separately doesn't require full set of data. Each PFP index provides valuable information about a particular area of interest, but by definition cannot provide a full picture of airport performance. PFP indexes don't consider differences in input/output prices and other operating environment conditions; leave factor substitution out of account [13], and so can be considered just as a good complementary research tool.

Stated weaknesses of PFP indexes led to development of methodologies which allow calculating overall efficiency values. All methodologies can be classified on the base of their principle (averaging or comparing with frontier values) and presence of a random component (deterministic or stochastic approaches). A classification of widely used methodologies is presented in the Table 1.

Table 1. Classification of methodologies used to estimation of firm's efficiency or productivity

\begin{tabular}{|l|c|c|}
\hline & Deterministic & Stochastic \\
\hline Averaging & $\begin{array}{c}\text { Total productivity factor } \\
\text { (TFP) }\end{array}$ & Classical regression models \\
\hline \multirow{3}{*}{ Frontier } & $\begin{array}{c}\text { Data envelopment analysis } \\
\text { (DEA) }\end{array}$ & $\begin{array}{c}\text { Stochastic Frontier analysis } \\
\text { (SFA) }\end{array}$ \\
& $\begin{array}{c}\text { Free disposal hull } \\
\text { (FDH) }\end{array}$ & $\begin{array}{c}\text { Distribution-free approach } \\
\text { (DFA) } \\
\text { Thick frontier approach } \\
\text { (TFA) }\end{array}$ \\
\hline
\end{tabular}


Methodologies, based on averaging of values, consider a relationship between weighted airport outputs and inputs. Total factor productivity (TFP) indexes use prices to weight input/output values, when regression estimates these 'weights' by minimizing the sum of squared residuals. Averaging methodologies assume that all airports in a sample operates efficiently, which obviously doesn't match the real situation when a difference between outputs of two airports with similar resources can be explained not only by a random component, but also by technical or managerial efficiency. Frontier-based methodologies (like data envelopment analysis or stochastic frontier analysis) allow inefficiency components by construction, but require a larger volume of data for estimation.

\section{Parametric approaches to airport benchmarking}

TFP indexes are ratios of weighted outputs to weighted inputs, where market prices are used as weights. Two most frequently used TFP indexes are Tornqvist index [23] and Caves, Christensen and Diewert (CCD) index [24], which can be considered as flexible forms of classical Laspeyres or Paasche indices.

Market prices, required for calculation of TFP indexes, are rarely available and valid, which can be a reason of a limited number of TFP applications to the airport industry. The most frequently cited researches, based on TFP, are the ATRS Global Airport Performance Benchmarking Reports [11] and related analytical studies [6]. Authors constructed a variable factor productivity index and used it for productivity comparison of airports around the world. Nyshadham and Rao [25] applied TFP indexes to estimation of European airports efficiency and compared the results with partial indexes. Gitto [26] applied TFP indexes as one of tools for analysis of Italian airports efficiency.

Charnes, Cooper, and Rhodes in 1978 [27] proposed a data envelopment analysis (DEA) approach to estimate overall company efficiency. DEA is a frontier approach, based on linear programming techniques, which allows directly taking airport inefficiency component into account. DEA constructs an efficiency frontier without market price values and without assumptions about a functional form of the frontier, which makes it easy-to-use and powerful efficiency estimation tool. The Malmquist index [24], defined using distance functions for a multi-input, multi-output technology, is frequently used to analyse airport efficiency changes over time.

DEA estimator is non-statistical by construction which makes it sensitive to data problems and prevents usage of popular research techniques like confidence intervals and hypothesis testing. Moreover, DEA estimator is biased upward [28] and inconsistent for non-convex frontiers. Simar and Wilson [28] suggested bootstrapping procedures to solve these problems and improve statistical properties of DEA estimates.

A practically important research area, which is lying outside the basic DEA model, is examination of factors influencing airport efficiency values (like airport ownership structure, hub status, etc.). A typical two-stage approach to deal with these factors includes calculation of DEA efficiency values and further their regression on explanatory factors. DEA efficiency values are obviously limited to the $[0,1]$ closed interval, so regressions with a censored dependent variable are used. Simar and Wilson [29] discussed properties of two most frequently used regression models - Tobit and truncated, and suggested an alternative double bootstrapping procedure.

DEA is the most frequently used academic approach to airports benchmarking. More than a hundred scientific researches, oriented on different practical and theoretical aspects of DEA model, were published during last two decades. Comprehensive literature reviews can be found in [20], [30], and [31]; in this paper we will just present DEA-based researches published in last years.

Gillen and Lall [32] published an analysis of US airports, based on the two-stage DEA approach with a second stage Tobit regression with environmental, structural and managerial variables. This research can be considered as a pioneering one and a base for many modern DEA-based airport benchmarking researches. Another frequently cited DEA application is Sarkis' US airports performance analysis [33].

Recently published studies include several country-specific DEA application for Spanish [34], [35], Greek [36], Malaysian [37], and Latin America's [38] airports. Barros et al. applied Gillen-Lall's approach to analyse airports in United States [39], in Argentine [40], in United Kingdom [30], [41], in Italy and Portugal jointly [42], and in Canada [43].

To the best of our knowledge, the most researched European countries in this aspect are Germany and Italy. German Aviation Research Society (GARS) published a set of researches ([44], [45], [22]), where the approach by Malmqvist-DEA was applied to a sample of German airports. Adler and Liebert [46] complemented DEA efficiency values with second stage OLS, Tobit, and truncated regressions on ownership, regulation, and management characteristics. Ulku, Muller, et al. [31], [47] analysed German airports applying Simar-Wilson's double bootstrapping procedure (among other research approaches). 
Gitto and Mancuso published some articles [26], [48-50] with application of Simar-Wilson's double bootstrapping procedure to Italian airports. Other recent DEA applications to Italian airports performance are presented by Barros and Dieke [51] and Malighetti et al. [52].

European airports efficiency was analysed by the University of Bergamo researchers [53], [54]. A special attention was devoted to competitive characteristics of the European airport network, which were included as a factor influencing airport efficiency in Simar-Wilson's model. Also DEA approach was applied to European airports by Pels et al. [16], [55].

DEA is not the only deterministic approach to efficiency estimation. The free disposal hull (FDH) method [56] is a popular extension of DEA, which relaxes DEA's assumption about a convex form of the frontier.

FDH has few applications to the airport industry. Holvad and Graham [57] applied FDH approach to analysis of European and Australian airports and discovered difference between DEA and FDH efficiency estimates for European airports.

However, since DEA and FDH are non-statistical, any deviation from the frontier is considered as inefficiency, making DEA estimates non-robust and exacting to data quality. Statistical models with a random component in specification solve this issue and allow applying standard powerful statistical techniques. Therefore statistical models (both averaging and frontier) became a more popular airport benchmarking tool during the last decade.

\section{Stochastic approaches to airport benchmarking}

The most popular statistical model is a classical regression, which estimates a relationship between the mathematical expectation of a dependent variable (usually output) and a set of explanatory variables (inputs). The classical regression requires a predefined functional form of this dependency. CobbDouglass function with a constant substitution elasticity and more flexible Translog are the two most frequently used functional forms in airport industry studies. The classical regression is based on averaging technique, so doesn't contain efficiency as a component of a model specification. In relation to airports, the classical regression represents a model of airports productivity, but not efficiency.

The pioneering airport regression analysis studies executed by Keeler [58], and Doganis and Thompson [59] deal with airports cost curve construction. Keeler estimated the Cobb-Douglass regression between operating costs and ATM on the base of pooled panel data of US airports. Doganis and Thompson also constructed Cobb-Douglass regression using WLU as an output and estimated its parameters for British airport cross-sectional data.

Later several similar studies with enhanced model specification (Translog) and estimation techniques (panel data econometrics) were published. Good literature reviews on this subject can be found in [60] and [61].

A statistical approach to frontier construction and efficiency estimation brought to development of a set of models: stochastic frontier model, thick frontier model, and distribution-free model are frequently used ones. Stochastic frontier analysis (SFA), the most popular approach, was presented by Aigner, Lovell, Schmidt [62], and Meeusen and van den Broeck [63] in 1977. This approach, rarely used for airports efficiency analysis before, recently became quite popular. The main strength of SFA is a statistical approach both to frontier and unit efficiency estimation, which makes easily available to apply confidence intervals, significance, hypothesis testing, and other statistical procedures. These advantages require mandatory specification of a frontier functional form and a law of efficiency distribution. Selection of a frontier form is usually made from Cobb-Douglass and Translog functions, and rarely includes more flexible, but data-consuming forms like Fourier-Flexible. Half-normal and truncated normal distribution laws are the most frequently used options for the efficiency (inefficiency) component. The latter (truncated) distribution allows direct inclusion of factors influencing airports efficiency into a model, and simultaneous estimation of all model parameters. In 2005 Greene [64] extended the SFA model with cross-form heterogeneity, which is considered as one of the most important problems with airport benchmarking. Greene's models (called true fixed and random effects models) estimation requires panel data, are currently available for airport applications.

First (to the best of our knowledge) SFA application to airports efficiency analysis was presented by Pels et al. [16], [65]. They applied homogeneous Cobb-Douglass frontier model to a sample of European airports and made comparison of estimation results with DEA-based estimates. Later Oum et al. [66] applied the Translog stochastic frontier model to estimate influence of airport ownership on its efficiency. 
During last three years number of studies significantly increased. Barros et al. presented a set of heterogeneous SFA applications to European [67], Japanese [68], and UK [30] airports. Voltes [61] analysed European, American, Oceania, and Asia-Pacific samples of airports, and later Spanish airports separately [69]. Muller, Ulku, and Zivanovic [47] within the bounds of German Aviation Performance project executed a comparison of British and German airports performance, estimated by different techniques (PFP, DEA, and SFA). Pavlyuk [70], [71] has analysed efficiency of European airports using the stochastic frontier model taking spatial competition among airports into consideration. Scotti applied homogeneous SFA model for Italian airports in his doctoral dissertation [8] and related articles [72].

Summing up SFA model applications, we can a growing academic interest to usage of this approach to airports efficiency estimation and a lack of studies with a heterogeneous frontier, which supposed to be a right choice for variegated environment of the airport business.

Two other stochastic frontier methods mentioned in the Table 1 are distribution-free and thick frontier approaches. Both methods remove restrictions of SFA related with mandatory specification of the frontier functional form and inefficiency distribution law and make estimation more flexible, but exacting to a volume of data. These strong requirements to data volume can be considered as one of the main reasons why there are no empirical applications of these methods to airport efficiency analysis.

Summarising this section, we note that the discussion about a correct approach to airport benchmarking is far from complication. There are several different approaches with their own advantages and shortcomings. The problem becomes even more complicated due to diverse nature of the airport business, allowing different approaches to definition of resources and outputs. Despite the complexity of the problem (or maybe thanks to this fact), airport benchmarking attracted a significant attention of world-wide scientific community.

\section{Spatial Competition among Airports: Theory and Applications}

\section{Airport competition and its elements}

The liberalisation of the European airport industry activated market mechanisms. Nowadays competition among airports can be considered as an integral part of the airport industry. According to the mainstream economical view, competition should act like a spur to increase efficiency of airports, forcing them to find better ways of demand fulfilment. During last two decades airport competition became a popular topic of theoretical and empirical studies, and widely recognised as a positive mechanism, leading to resource saving, service quality improvements, and development of the industry as whole. Although this thesis is commonly acknowledged, there are several not unfounded critical opinions in literature. Some authors [73] state that increasing competition leads airports to lack of critical mass (traffic volume required for covering obligatory operating costs), excessive capacities and swallowing up subsidies as a result. Regardless of its consequences, competition process among airports is very diverse. There is a wide variety of ways in which airports compete (the list is compiled on the base of Tretheway and Kincaid [74] and Forsyth [75] studies):

- Competition for passengers with neighbour airports on a shared local market.

- Competition as a destination point (for tourists, businesses, etc.).

- Competition for passengers with other transport modes (high-speed railways, ferries, etc.).

- Competition for connecting traffic.

- Competition for cargo traffic.

- Competition for contracts with airlines.

- Competition of non-aeronautical services (car parking, retail, maintenance).

All presented types of airports competition already play an important role in industry regulation; first two types (competition for passengers on a local market and for visitors as a destination point) are attracting special interest due to industry-specific spatial settings.

Although the presence of competition effects in the airport industry is widely acknowledged, there are little empirical evidences on a strength of competition among airports. Forsyth [76] states mild competition among airports and specifies a set of factors limiting it:

1. Common ownership of neighbour airports. Frequently airports in major European cities (London, Berlin) are owned by one proprietor, which makes competition among them imperfect (if any).

2. Scale economy is very important in the airport industry and it's difficult for small or new airports to reach the optimal traffic volume. 
3. Indivisibility of airport infrastructure complicates a reaction of airport management for demand fluctuations. Airport scale can't be increased (or reduced) continuously or by small pieces under infrastructure restrictions. For example, building of a new runway significantly increases airport scale, but requires significant capital investments at once.

4. Environmental and other legal barriers prevent entry of new airports (to ensure a competitive market).

5. Congestion of some airports makes them insensitive for demand changes.

6. Different airport regulation regimes and government subsidies make competition among airports imperfect.

There are some other sceptical opinions about current strength of airport competition [77], [78]. Despite the specified obstacles for airport competition and widely used regulation mechanisms as a competition replacement, there are a number of strengthening competition indications in European airport industry.

\section{Evidences of strengthening airport competition in Europe}

A positive influence of low-cost carriers' (LCC) activity on airport competition is well researched [82], [83], [84]. The entry of low-cost carriers on the European market changed an established airport hierarchy and encouraged the development of small and medium secondary and regional airports. Also LCC catalysed a substantial growth of direct connections between airports. These LCC effects (among others) stimulated a competitive activity in the European airport industry.

Number of new airport entries to the market also can be considered as an evidence of increasing competition. Muller-Rostin et al. [9] estimated the overall level of competition in the airport industry using numbers of newly opened (entry) and closed (exit) airports as indicators. In this study authors investigated competition on a by-country basis for Germany, Italy, UK, Spain, Poland, and jointly for other Eastern European countries.

Strengthening competition on the airport market is also attested by increasing marketing efforts of airport management. According to Tretheway and Kincaid [74], the ratio of marketing staff per passenger in selected UK airports was significantly increased.

An indirect, but meaningful evidence of intensifying competition is an interest to market power estimation from government competition authorities. During last years competition commissions, previously considered airports as natural monopolies, requested some airport market power researches. UK Competition Commission estimated the market power of London Stansted [85] and currently implementing a similar research for Heathrow, Gatwick, and Stansted [86]. The team of the German Airport Performance project executed a research of the Amsterdam Schiphol airport's market power for Netherlands Competition Authority [87] and discovered a slightly increasing competition pressure the airport exposed.

A specific feature of European transportation market is well-developed railways and motorways supported by stable people habits of their usage. Railways and motorways in this context should be considered not only as competitors for air transport, but also as a factor, increasing competition among airports for multi-modal trips. The increasing mobility of population allows airports to compete for passengers living far from airport locations.

\section{Theoretical background of spatial competition}

Competition among airports in different areas (for passengers, for airlines, etc.) is different by its nature and has various sources and effects. To the best of our knowledge, one of the most underresearched aspects of airport competition is a spatial one.

Spatial competition is mainly concerned with the locational interdependence among economic agents. The theory of spatial competition is well established and there are a significant number of its applications in different economic areas. Recently models of spatial competition were applied to movie theatres, gas stations, retail places, hospitals, country regions and others, but the airport industry is still weakly covered. Open airport market and increasing number of airports from one side and airports unalterable locations from another create good background for spatial completion in this sector.

A study, frequently cited as a pioneering in the areas of spatial competition, was presented by Hotelling in 1929 [88]. Hotelling considered a basic case of two firms producing homogeneous goods in different locations on a line and stated a key question about competition among firms and their efforts to differentiate from each other. Later the idea of Hotelling's model was developed in different ways. 
D'Aspermont et al. [89] introduced quadratic transportation costs for the model, which allowed its equilibrium solution. Salop [90] enhanced the model by replacing the linear locational structure with a two-dimensional circular one. The limitation of homogeneous goods, inadmissibly restrictive for the airport industry, also was addressed. Irmen and Thisse [91] introduced a multi-dimensional model where dimensions can have different weights. They proved that in the equilibrium point a firm differentiate itself from competitors in one dimension, but locate in the centre (close to other firms) for all other dimensions.

Correctness of Irmen and Thisse's model has several corroborations in the airport industry. A set of dimensions can include a price segment of served airlines (from LCC to regular and elite), traffic types (from cargo to connecting or direct passenger flights), flight destinations (from domestic to short- and long-haul international), and airport geographical location. Looking at the European airport industry, we can discover several examples where airports are differentiated in one of these dimensions, but located closely in others. There are European cities with major and secondary airports (London, Paris, Berlin), where the secondary airport is typically served by LCC (and differentiated in this dimension). Another example is airports in Baltic States' capital cities (Riga, Tallinn, Vilnius), which are differentiated geographically and don't have to distance themselves from each other for other dimensions.

A mode of airport competition (quantity-based Cournot competition or price-based Bertrand competition) is also a subject of academic researches [92], [93]. Biscia and Mota [94] presented an outstanding review of studies on both Cournot and Bertrand competition modes in spatial settings.

\section{Empirical studies of airport spatial competition}

Empirical estimation of spatial competition among airports is weakly covered by researches. There are two different ways in which airports can compete spatially:

- $\quad$ as a departure point for local population;

- $\quad$ as a destination point for tourists and businesses.

Estimation of the first aspect of spatial competition among airports is usually based on the conception of catchment area. Airport industry researches define airport's catchment area as a geographical zone containing potential passengers of the airport. Usually the geographical definition of airport's catchment area is supplemented with demographic indicators such as population, employment, income and others [95].

Catchment area's radius can be defined in different ways:

- by geographical distance;

- by travel time;

- by travel cost.

The metrics are used linearly or with time (distance) decay functions.

Several empirical researches used overlapping catchment areas as an indicator of spatial competition among neighbour airports. Starkie [80] studied competition between airports for hinterlands as a degree of the airports' catchment areas overlapping (Figure 1) and later applied this approach in his further researches [96], [97].

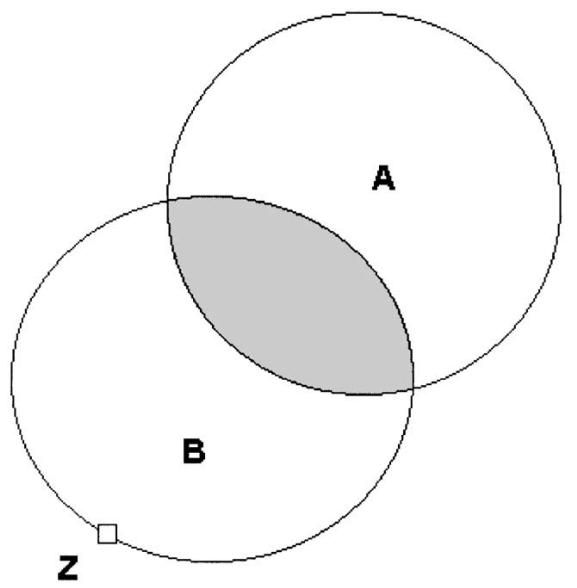

Figure 1. Competition and catchment areas. Source: Starkie, 2002 [80] 
Analysis of overlapping catchment areas was supplemented by additional characteristics of airport services like flights frequency, destinations, etc. Strobach [98] constructed an index of spatial airports competition for a particular destination point using a set of factors, weighted by their (author-defined) importance. The factors include transport accessibility (distance and time values for private transport and cost and time values for public transport), traffic characteristics (frequency of flights to a selected direction, minimum connecting time, numbers of gates and check-ins), and characteristics of convenience (parking spaces, terminal area, area of shopping and services). Malina [99] suggested a substitution coefficient, which "defined as the share of inhabitants within the relevant regional market of an airport that consider another airport (...) to be a good substitute from their perspective as well". Hancioglu [78] investigated competition between Dusseldorf and Cologne/Bonn airports using Malina's airports substitution coefficient, mainly based on overlapping catchment areas, and a custom survey of passengers' origin regions. Pavlyuk [70] suggested constructing multiple catchment areas of an airport for different flight destinations. Bel and Fagenda [100], and Adler and Liebert [46] used number of nearby airports as a simple indicator of competition pressure.

Another popular approach to estimation of completion pressure is interviews with experts and airport management [101-103]. This approach is very useful for initial analysis of the competition pressure, but has an obvious shortcoming of subjectivity as well as quantitative measurement problems.

The second way of spatial competition among airports is based on their function to be an intermediate destination point. Leisure and business travellers manage their trips and define intermediate connection points (including airports). This subject of their choice is wider than selection between two (or more) airports in a destination city and relates to trip's route as whole. For example, for a saving trip from London to Moscow travellers can choose between Riga and Tallinn airports as an airline-railway transfer point. Note that the essence of this way of competition is not necessary spatial, but spatial effect can take place in some cases. To the best of our knowledge, there are no studies containing empirical estimation of this aspect of spatial competition between airports.

\section{Spatial competition and airports efficiency} airports.

There are few empirical studies of a relationship between spatial competition and efficiency of

Borins and Advani [102] used interviews with airport managers to estimate levels of competition of two types - transferring traffic and catchment areas. Estimated competition levels were included into two classical regression models with passenger and airline orientations. Both competition types are found significantly positive in both models, so authors concluded positive influence of competition on airports activity.

Jing [104] analysed efficiency of Asian cargo airports using the stochastic frontier approach and including competition into consideration. A suggested competitiveness index was constructed on the base of airports ranking by locational, facility, service quality, charges, staff quality, connectivity, and market environment factors. Although airport's geographical location was included into the index, spatial effects are unexamined in the paper.

Pavlyuk [70] suggested index of competition, based on overlapping catchment areas, included it into the stochastic frontier model, and discovered a positive effect of competition pressure on efficiency for a sample of European airports. Non-linear spatial interdependence was investigated in author's further research [71] and a multi-tier model of competition and cooperation effects was suggested. The model estimates provide both positive and negative effects depending on a distance tier.

Scotti et al. [8], [54], [72] suggested an index of competition between two airports on the base of a share of population living in an overlapped region of the airports' catchment areas. Competition was calculated separately for every destination point (exact or reasonably close) and combined into the general competition index using available seats shares as weights. The suggested index of competition was included in a set of inefficiency determinants of a multi-output stochastic frontier model. Estimating parameters of this model for a sample of Italian airports, authors concluded a significant negative relationship between competition pressure and airport efficiency. Authors explained this fact by overcapacity of airports. Airports, acting in more competitive environment, captured limited benefits of air transport postliberalisation traffic growth, when monopolistic airports easier filled their capacity and improved their technical efficiency.

Adler and Liebert [105] investigated an influence of competition on airport efficiency using a twostage DEA model. A level of competition was included into the second stage regression as number of significant airports within a catchment area and showed up as a significant factor for results of different regulation forms. The spatial specification of the second stage regression was tested by author, but solely for justifying of the model's robustness. 


\section{Spatial econometrics}

Recently developed theory of spatial econometrics [106] is a modern and powerful tool for analysis of spatial relationships of different types. Spatial econometrics deals with spatial interaction (a specific form of which is a spatial competition) and spatial heterogeneity in regression models. A key technical component of spatial model is a matrix of spatial weights, which contains values of spatial interdependency (frequently inversed distances) for every pair of sample objects. Methods of spatial econometrics are frequently used for analysis of competition effects in spatial settings [107], but, to the best of our knowledge, there is only one application [71] of these methods to analysis of airport productivity and efficiency.

Summarising the section, we can note that the nature of competition between airports is very complex and this subject is weakly covered by empirical researches. Due to discussed reasons we expect that the competition between airports in Europe will be strengthening in nearest future, and this fact will intensify theoretical and empirical researches in this area. Competition, being one of the best drivers of economic efficiency, should be included into airport benchmarking procedures. The role of spatial competition among neighbour airports is also expected to grow, and methods of spatial econometric can be applied for analysis of airports efficiency.

\section{Conclusions and Future Research Directions}

During last two decades airport benchmarking attracted a significant attention of the scientific community. Many theoretical and practical studies addressed to this problem are published recently, but methodological base and even problem specification issues are far from a consensus. The airport business is usually considered as an intermediary between population and air carriers, and it makes specification of airport resources and activity results not straightforward. Passengers and cargo transferred by an airport, airline movements served, environmental emission and noise, and other airport activity aspects are included into studies either as resources or as outputs of the business.

A range of quantitative methods used for airport benchmarking is reasonably wide. Productivity indicators (PFP and TFP), deterministic (DEA, FDH) and stochastic (SFA) frontier approaches are widely used. Partial productivity indicators (APM per employee, operational costs per WLU) are frequently used for initial analysis of airport efficiency, but reflect only a particular aspect of the business. Modern approaches to estimation of overall airport efficiency are based on the frontier concept. The majority of airport studies utilise deterministic frontier DEA approach to benchmarking, but during last three years number of stochastic SFA approach applications is increased significantly. We associate this interest to stochastic frontier applications with recent theoretical SFA developments, which allow taking into account a heterogeneous nature of airport production. Considering the complexity of the airport business, we can conclude a significant research field in this direction.

Discussions about competition among airports are also intensified last years. Despite several reasonable sceptical opinions about the existence of significant airport competition, there are a number of studies related to empirical evidences of competition. A structure of airport competition is composite. Airports compete for passengers, contracts with airlines, for arriving passenger traffic, for transferring traffic, for cargo transportation and others. Each component of airport competition can be considered as a separate topic of research, with its own features and problems. Spatial competition, based on locational interrelation between airports, is a special type of competition, which is addressed by several recent researches. The most popular spatial approach is based on the catchment area concept. This concept allows authors to estimate and analyse a level of spatial competition among airports. The theory of spatial competition is well-developed, but number of its empirical applications in the airport industry is very limited, which creates an extensive area for further researches.

Finally, an empirical relationship between spatial competition and efficiency of airports is also weakly researched. According to the mainstream economics, competition is the best way to force agents to improve their efficiency, but a power of this mechanism in the airport industry is almost unstudied. A small number of empirical studies don't allow make a comprehensive conclusion about the subject. The methodological base of this kind of researches is also scanty, so influence of spatial competition on airports efficiencies is an extensive and complicated research topic. We seem that application of spatial econometrics to this area will enhance the methodological base of analysis and lead to practically important results. 


\section{References}

1. European Commission. (1992). Council Regulation on licensing of air carriers (No 2407/92). Official Journal of the European Union (Legislation): The Publications Office of the European Union.

2. European Commission. (1992). Council Regulation on access for Community air carriers to intraCommunity air routes (No 2408/92). Official Journal of the European Union (Legislation): The Publications Office of the European Union.

3. European Commission. (1992). Council Regulation on fares and rates for air services (No 2409/92). Official Journal of the European Union (Legislation): The Publications Office of the European Union.

4. Fu, X., Oum, T.H., Zhang, A. (2010). Air Transport Liberalization and Its Impacts on Airline Competition and Air Passenger Traffic. Transportation Journal, 49(4), 24-41.

5. European Conference of Ministers of Transport, Organisation for Economic Co-operation and Development, International Transport Forum. (2009). Competitive interaction between airports, airlines and high-speed rail. Paris: OECD/ITF.

6. Oum, T.H., Adler, N., Yu, C. (2006). Privatization, corporatization, ownership forms and their effects on the performance of the world's major airports. Journal of Air Transport Management, 12(3), 109-121.

7. Oum, T.H. (1992). Concepts, methods and purposes of productivity measurement in transportation. Transportation Research Part A: Policy and Practice, 26(6), 493-505.

8. Scotti, D. (2011). Measuring Airports' Technical Efficiency: Evidence from Italy, PhD thesis, University of Bergamo, Italy

9. Müller-Rostin, C., Niemeier, H.M., Ivanova, P., Müller, J., Hannak, I., Ehmer, H. (2010). Airport Entry and Exit: A European Analysis. In Airport Competition: The European Experience (pp. 27-46). England, Farnham: Ashgate Publishing Limited,

10. European Commission. (2006). Commission Regulation laying down a common charging scheme for air navigation services Text with EEA relevance (No 1794/2006). Official Journal of the European Union (Legislation): The Publications Office of the European Union.

11. Oum, T.H., Yu, C., Choo, Y. (2011). ATRS Global Airport Performance Benchmarking Project, The Air Transport Research Society Vancouver, Canada: The Air Transport Research Society.

12. Merkert, R., Pagliari, R., Odeck, J., Brathen, S., Halpern, N., Husdal, J. (2010). Benchmarking Avinor's Efficiency, Møreforsking Molde AS, 1006. Molde, Norway: Møreforsking Molde.

13. Civil Aviation Authority. (2000). The Use of Benchmarking in the Airport Reviews. London, UK: CAA.

14. O’Sullivan, A., Sheffrin, S.M. (2003). Economics: principles in action. Needham, Mass.: Prentice Hall.

15. Doganis, R. (1992). The airport business. London: Routledge.

16. Pels, E., Nijkamp, P., Rietveld, P. (2003). Inefficiencies and scale economies of European airport operations. Transportation Research Part E: Logistics and Transportation Review, 39, 341-361.

17. Zenglein, M.J., Müller, J. (2007). Non-Aviation Revenue in the Airport Business-Evaluating Performance Measurement for a Changing Value Proposition. Berlin, Germany: Berlin School of Economics.

18. Yu, M. (2004). Measuring physical efficiency of domestic airports in Taiwan with undesirable outputs and environmental factors. Journal of Air Transport Management, 10(5), 295-303.

19. Pathomsiri, S., Haghani, A., Dresner, M., Windle, R.J. (2008). Impact of undesirable outputs on the productivity of US airports. Transportation Research Part E: Logistics and Transportation Review, 44(2), 235-259.

20. Liebert, V., Niemeier, H.M. (2011). Benchmarking of Airports-A Critical Assessment. In Proceedings of the $12^{\text {th }}$ World Conference on Transport Research, 11-15 July 2010 (p. 46) Lisbon, Portugal: WCTRS.

21. Hirschhausen, C., Cullman, A. (2005). Questions to Airport Benchmarkers - Some Theoretical and Practical Aspects Learned from Benchmarking Other Sectors. In the German Aviation Research Society Workshop, 24-25 November 2005 (p.16). Vienna, Austria: German Aviation Research Society.

22. Abdesaken, G., Cullman, A. (2006). The Relative Efficiency of German Airports. In the GARS Amsterdam Student Workshop, 7 October 2006 (p. 36). Amsterdam: German Aviation Research Society. 
23. Törnqvist, L. (1981). Collected scientific papers of Leo Törnqvist. Helsinki: Research Institute of the Finnish Economy.

24. Caves, D.W., Christensen, L.R., Diewert, W.E. (1982). Multilateral Comparisons of Output, Input, and Productivity Using Superlative Index Numbers. The Economic Journal, 92(365), 73-86.

25. Nyshadham, E.A., Rao, V.K. (2000). Assessing Efficiency of European Airports: A Total Factor Productivity Approach. Public Works Management \& Policy, 5(2), 106-114.

26. Gitto, S. (2008). The measurement of productivity and efficiency: theory and applications. $\mathrm{PhD}$ thesis, University of Rome "Tor Vergata," Rome, Italy.

27. Charnes, A., Cooper, W.W., Rhodes, E. (1978). Measuring the efficiency of decision making units. European journal of operational research, 2(6), 429-444.

28. Simar, L., Wilson, P.W. (2000). Statistical Inference in Nonparametric Frontier Models: The State of the Art. Journal of Productivity Analysis, 13(1), 49-78.

29. Simar, L., Wilson, P.W. (2007). Estimation and inference in two-stage, semi-parametric models of production processes. Journal of econometrics, 136(1), 31-64.

30. Barros, C.P. (2008). Technical efficiency of UK airports. Journal of Air Transport Management, 14(4), 175-178.

31. Ulku, T. (2009). Efficiency of German Airports and Influencing Factors. MSc thesis. Humboldt University, Berlin, Germany.

32. Gillen, D., Lall, A. (1997). Developing measures of airport productivity and performance: an application of data envelopment analysis. Transportation Research Part E: Logistics and Transportation Review, 33(4), 261-273.

33. Sarkis, J. (2000). An analysis of the operational efficiency of major airports in the United States. Journal of Operations Management, 18(3), 335-352.

34. Tapiador, F., Mateos, A., Marti-Henneberg, J. (2008). The geographical efficiency of Spain's regional airports: A quantitative analysis. Journal of Air Transport Management, 14, 205-212.

35. Martin, J.C., Roman, C. (2001). An application of DEA to measure the efficiency of Spanish airports prior to privatization. Journal of Air Transport Management, 7(3), 149-157.

36. Psaraki-Kalouptsidi, V., Kalakou, S. (2011). Assessment of efficiency of Greek airports. Journal of Airport Management, 5(2), 170-186.

37. Razali, S.R., Shah, M.Z. (2010). Performance Measurement of Malaysian Airports using DEA method. In Proceedings of Malaysian Universities Transportation Research Forum and Conferences, 21 December 2010 (pp. 487-493). Malaysia: University Tenaga Nasional.

38. Perelman, S., Serebrisky, T. (2010). Measuring the technical efficiency of airports in Latin America. Policy Research Working Paper WPS5339. Liege, Belgium: The World Bank.

39. Barros, C.P., Assef, A. (2009). Productivity change in USA airports: the Gillen and Lall approach revisited. Working Paper 22/2009/DE/UECE. Lisbon, Portugal: School of Economics and Management.

40. Barros, C.P., Assaf, A., Lipovich, G.A. (2010). Productivity Analysis of Argentine Airports. Working Paper. Lisbon, Portugal: School of Economics and Management.

41. Barros, C.P., Weber, W.L. (2009). Productivity growth and biased technological change in UK airports. Transportation Research Part E: Logistics and Transportation Review, 45(4), 642-653.

42. Barros, C.P., Peypoch, N. (2007). A comparative analysis of productivity change in Italian and Portuguese airports. Working Paper 006/2007/DE. Lisbon, Portugal: School of Economics and Management.

43. Barros, C.P., Peypoch, N., Villard, P. (2011). Productivity changes in Canadian airports and technological change analysis. Working Paper 05/2011/DE/UECE. Lisbon, Portugal: School of Economics and Management.

44. Kamp, V., Niemeier, H., Schmidt, P. (2004). Benchmarking of German Airports - Some first Results. In the GARS Research Seminar "How to Make Slot Markets Work" (p. 17). Bremen, Germany: GARS.

45. Kamp, V. (2007). Airport Benchmarking - An Empirical Research on the Performance Measurement of German Airports with Data Envelopment Analysis. Aerlines e-zine edition, 36, 1-4.

46. Adler, N., Liebert, V. (2011). Joint Impact of Competition, Ownership Form and Economic Regulation on Airport Performance. Bremen: Jacobs University.

47. Muller, J., Ulku, T., Zivanovic, J. (2009). Privatization, restructuring and its effects on performance: A comparison between German and British airports. German Airport Performance Project, Working Paper 16, Germany: GAP.

48. Curi, C., Gitto, S., Mancuso, P. (2009). Managerial assessment of Italian airport efficiency: a statistical DEA approach. Discussion Paper. Rome, Italy: University of Tor Vergata. 
49. Gitto, S., Mancuso, P. (2010). Airport efficiency: a DEA two stage analysis of the Italian commercial airports. Paper 34366. Munich, Germany: MPRA.

50. Curi, C., Gitto, S., Mancuso, P. (2011). New Evidence on the Efficiency of Italian Airports: A Bootstrapped DEA Analysis. Socio-Economic Planning Sciences, 45(2), 84-93.

51. Barros, C.P., Dieke, P. (2007). Performance evaluation of Italian airports: A data envelopment analysis. Journal of Air Transport Management, 13(4), 184-191.

52. Malighetti, P., Martini, G., Paleari, S., Redondi, R. (2007). Efficiency of Italian airports management: the implications for regulation. Working Paper. Italy: University of Bergamo.

53. Malighetti, P., Martini, G., Paleari, S., Redondi, R. (2008). The efficiency of European airports: Do the importance in the EU network and the intensity of competition matter? Working Paper 04-2008. Bergamo, Italy: University of Bergamo, Department of Economics and Technology Management.

54. Malighetti, P., Martini, G., Paleari, S., Redondi, R. (2009). The Impacts of Airport Centrality in the EU Network and Inter-Airport Competition on Airport Efficiency. Paper 17673. Munich, Germany: MPRA.

55. Suzuki, S., Nijkamp, P., Pels, E., Rietveld, P. (2009). Comparitive Performance Analysis of European Airports by Means of Extended Data Envelopment Analysis. Discussion Paper 2009-024/3. The Netherlands: Tinbergen Institute.

56. Deprins, D., Simar, L., Tulkens, H. (1984). Measuring labor-efficiency in post offices. In The Performance of Public Enterprises: Concepts and Measurement (pp. 243-267). Amsterdam: NorthHolland.

57. Holvad, T., Graham, A. (2000). Efficiency Measurement for Airports. In the Annual Transport Conference, Aalborg University, Denmark, 28-29 August 2000 (pp. 331-343). Denmark: Aalborg University.

58. Keeler, T. (1970). Airport Costs and Congestion. The American Economist, 14(1), 47-53.

59. Doganis, R., Thompson, G. (1974). Establishing Airport Cost and Revenue Functions. Aeronautical Journal, 78, 285-304.

60. Jeong, J. (2005). An investigation of operating cost of airports: focus on the effect of output scale. MSc thesis, The University of British Columbia, Canada.

61. Voltes, A.J. (2008). Stochastic frontier estimation of airports' cost function. PhD thesis, The University of Las Palmas de Gran Canaria, Spain.

62. Aigner, D., Lovell, C., Schmidt, P. (1977). Formulation and estimation of stochastic frontier production function models. Journal of econometrics, 6(1), 21-37.

63. Meeusen, W., van der Broeck, J. (1977). Efficiency Estimation from Cobb-Douglas Production Function with Composed Error. International Economic Review, 8, 435-444.

64. Greene, W. (2005). Reconsidering heterogeneity in panel data estimators of the stochastic frontier model. Journal of Econometrics, 126(2), 269-303.

65. Pels, E. (2001). Relative efficiency of European airports. Transport Policy, 8(3), 183-192.

66. Oum, T.H., Yan, J., Yu, C. (2008). Ownership forms matter for airport efficiency: A stochastic frontier investigation of worldwide airports. Journal of Urban Economics, 64(2), 422-435.

67. Barros, C.P., Marques, R.C. (2008). Performance of European Airports: Regulation, Ownership and Managerial Efficiency. Working Paper 25/2008/DE/UECE. Lisbon, Portugal: School of Economics and Management.

68. Barros, C.P., Managi, S., Yoshida, Y. (2008). Technical Efficiency, Regulation, and Heterogeneity in Japanese Airports. Working Paper 43/2008/DE/UECE. Lisbon, Portugal: School of Economics and Management.

69. Martín, J.C., Román, C., Voltes-Dorta, A. (2009). A stochastic frontier analysis to estimate the relative efficiency of Spanish airports. Journal of Productivity Analysis, 31, 163-176.

70. Pavlyuk, D. (2009). Spatial competition pressure as a factor of European airports' efficiency. Transport and Telecommunication, 10(4), 8-17.

71. Pavlyuk, D. (2010). Multi-tier spatial stocjastic frontier model for competition and cooperation of European airports. Transport and Telecommunication, 11(3), 57-66.

72. Malighetti, P., Martini, G., Scotti, D., Volta, N. (2010). The impact of airport competition on technical efficiency: A Stochastic Frontier Analysis applied to Italian airports. Paper 24648. Munich, Germany: MPRA.

73. Heymann, E., Vollenkemper, J., Frank, H.J., Walter, N. (2005). Expansion of regional airports: Misallocation of resources. Deutsche Bank Research, Germany.

74. Tretheway, M., Kincaid, I. (2005). Competition between airports in the new Millennium: what works, what doesn't work and why. In The 8th Hamburg Aviation Conference, 16-18 February 2005 (p. 18). Hamburg, Germany: InterVISTAS Consulting Inc. 
75. Forsyth, P., Gillen, D., Müller, J., Niemeier, H. (2010). Airport Competition: The European Experience. England: Farnham: Ashgate Publishing Limited.

76. Forsyth, P. (2006). Airport competition: regulatory issues and policy implications. In Competition policy and antitrust, Vol. 1, (pp. 347-367). Amsterdam; Boston: Elsevier.

77. Barrett, S. (2000). Airport competition in the deregulated European aviation market. Journal of Air Transport Management, 6, 13-27.

78. Hancioglu, B. (2008). The Market Power of Airports, Regulatory Issues and Competition between Airports. Working Paper. German Airport Performance Project. Germany: GAP.

79. Czerny, A.I. (2006). Price-cap Regulation of Airports: Single-till Versus Dual-till. Journal of Regulatory Economics, 30(1), 85-97.

80. Starkie, D. (2002). Airport regulation and competition. Journal of Air Transport Management, 8, 63-72.

81. Bel, G., Fageda, X. (2009). Privatization, regulation and airport pricing: an empirical analysis for Europe. Journal of Regulatory Economics, 37, 142-161.

82. Dresner, M., Lin, J.-S., Windle, R. (1996). The Impact of Low Cost Carriers on Airport and Route Competition. Journal of Transport Economics and Policy, 30(3), 309-328.

83. Trzepacz, P. (2007). Spatial aspects of air transportation liberalization-changes in European airport hierarchy. Bull. Geography, 8, 163-177.

84. Pels, E., Njegovan, N., Behrens, C. (2009). Low-cost airlines and airport competition. Transportation Research E, 45, 335-344.

85. Competition Commission. (2008). Stansted Airport Q5 price control review. UK: Competition Commission.

86. Civil Aviation Authority. (2011). Heathrow, Gatwick and Stansted Airports Q6 review. UK: CAA.

87. Muller, J., Bilotkach, V., Fichert, F., Niemeier, H.M., Pels, E., Polk, A. (2010). The economic market power of Amsterdam Airport Schiphol. The Netherlands:The Netherlands Competition Authority.

88. Hotelling, H. (1929). Stability in competition. The Economic Journal, 39(153), 41-57.

89. D' Aspremont, C., Gabszewicz, J.J., Thisse, J.-F. (1979). On Hotelling's "Stability in Competition," Econometrica, 47(5), 1145-1150.

90. Salop, S. (1979). Monopolistic competition with outside goods. The Bell Journal of Economics, 10(1), 141-156.

91. Irmen, A., Thisse, J.-F. (1998). Competition in Multi-characteristics Spaces: Hotelling Was Almost Right. Journal of Economic Theory, 78(1), 76-102.

92. Van Dender, K. (2005). Duopoly prices under congested access. Journal of Regional Science, 45(2), 343-362.

93. Haskel, J., Iozzi, A., Valletti, T.M. (2011). Market structure, countervailing power and price discrimination: the case of airports. Discussion Paper 2011/03. London, UK: Imperial College.

94. Biscaia, R., Mota, I. (2011). Models of Spatial Competition: a Critical Review. Working Paper 411. Portugal: Department of Economics, University of Porto.

95. Department of Transport. (2004). Regional and Small Airports Study. TP 14283B. Canada: Department of Transport.

96. Starkie, D. (2009). The airport industry in a competitive environment: A United Kingdom Perspective. In Competitive Interaction between Airports, Airlines and High-Speed Rail (pp. 67-93). London, UK: OECD Publishing.

97. Civil Aviation Authority. (2011). Catchment area analysis. Working Paper. UK: Civil Aviation Authority.

98. Strobach, D. (2006). Competition between airports with an application to the state of BadenWürttemberg. Working Paper 272/2006. Germany: University of Hohenheim.

99. Malina, R. (2006). Competition and regulation in the German airport market. Discussion Paper 10. Germany: Institute of Transport Economics.

100. Bel, G., Fageda, X. (2009). Factors explaining charges in European airports: Competition, market size, private ownership and regulation. Working Paper 2009-31. Madrid, Spain: Fundación de Estudios de Economía Aplicada.

101. Air Transport Group. (2002). Study on Competition between Airports and the Application of State Aid Rules. Final Report 2002/287. UK: ATG.

102. Borins, S., Advani, A. (2002). Managing airports: a test of the New Public Management. International Public Management Journal, 4(1), 91-107. 
103. Gillen, D., Niemeier, H. M. (2006). Airport Economics, Policy and Management: The European Union. In the Fundación Rafael del Pino Workshop on Infrastructure Economics: a Comparative Analyses of the Main Worldwide Airports, Madrid, Spain (p. 53). Madrid, Spain: Rafael del Pino Foundation.

104. Jing, X. Y. (2007). Benchmarking competitiveness of cargo airports. MSc thesis, National University of Singapore, Singapore.

105. Adler, N., Liebert, V. (2010). Competition and regulation (when lacking the former) outrank ownership form in generating airport efficiency. In The GAP workshop "Benchmarking of Airports," Berlin, Germany, 25-26 November 2010 (p. 27). Berlin, Germany: GAP.

106. Anselin, L. (1988). Spatial econometrics: methods and models. Dordrecht: Kluwer Academic Publishing.

107. Arbia, G. (2006). Spatial econometrics: statistical foundations and applications to regional convergence. Berlin: Springer. 